\title{
Autoría, autoridad y verdad. Apuntes para una nueva lectura ‘en frío’ de la polémica Menchú-Stoll
}

Autorship, Authority and Truth.

Notes for a new 'calm' reading of the Menchú-Stoll polemic

\section{MERCÉ PICORNELL}

UNIVERSITAT DE LES ILLES BALEARS · m.picornell@uib.cat

Doctora y profesora del Departament de Filologia Catalana i Lingüística General en la Universitat de les Illes Balears en la ciudad de Palma. Investiga y trabaja en el Grup de recerca LiCETC. Es autora de Discursos testimonials en la literatura catalana recent (2002) y Continuitats i desviacions. Debats crítics sobre la cultura catalana en vértex 1960/1970 (2013). Su tesis doctoral tuvo como tema Política i poética de l'etnoficción. Escriptura testimonial i representació de la veu subalterna (2003).

Resumen: Este artículo versa sobre las condiciones que afectan la recepción de los textos que han sido ubicados bajo la rúbrica genérica testimonio en relación a la construcción de su autoría y de su condición de "verdad". El análisis se concreta a partir de los procesos de interpretación que afectan un caso polémico, el de la recepción del testimonio mediado por Elizabeth Burgos, Me llamo Rigoberta Menchú $y$ así me nació la conciencia (1983) una vez su referencialidad fue puesta en cuestión por el antropólogo David Stoll en el libro Rigoberta Menchu and the Story of All Poor Guatemalans (1999). Se parte de la hipótesis que toda posición de autor depende de elementos pragmáticos condicionados tanto por la filiación genérica o disciplinaria del texto en cuestión como por el lugar --social, político, simbólico-- que ocupa quien firma la obra en un determinado entorno.

Palabras clave: testimonio, autoridad etnográfica, voces subalterna y autoría plural.
Abstract: This paper deals with the factors that affect the reception of those texts linked to the genre testimonio, in relation to the construction of their authorship and truth. It analyzes the interpretation processes that affect a controversial case: the reception of the work of Elizabeth Burgos, Me llamo Rigoberta Menchú y así me nació la conciencia (1983), once its documentary value was questioned by the anthropologist David Stoll in his book Rigoberta Menchú and the Story of All Poor Guatemalans (1999). The testimonio is an interesting genre where to show how the "author" function depends on pragmatic factors conditioned by the generic or disciplinary affiliation of the text, as well as by the social, political or symbolical place occupied by the person(s) who sign(s) the book.

Key words: testimonial writing, etnographic authority, subaltern voices and plural authorship. 
Mercé Picornell. Autoría, autoridad y verdad...

Si algo caracteriza el proceso de definición del testimonio como género es su vocación de crear un nuevo espacio de enunciación para permitir la expresión de aquellos cuyas voces y cuya voluntad de representación política no se acomodan en los géneros preexistentes. Por este motivo, muchas de las obras ubicadas bajo la rúbrica del testimonio se sitúan al margen de las disciplinas académicas ocupadas tradicionalmente de la representación cultural --la antropología, la historia, e incluso la literatura--, que los promotores del género consideran "viciadas" por el uso hegemónico del poder. ${ }^{1}$ En realidad, sin embargo, la mayoría de testimonios beben de muchos de los métodos de los géneros preexistentes para construirse. De hecho, testimonios canónicos como el inicial del antropólogo y escritor Miguel Barnet, Biografía de un cimarrón (1966), se diferencian de otros relatos biográficos o de historia oral en uso en las ciencias sociales, más por una voluntad de garantizar el estatuto políticamente representativo y estéticamente válido de la voz de los individuos cuya experiencia se relata que no por diferencias formales claras. La ambigüedad intrínseca a la ubicación fronteriza de los discursos testimoniales hace que los textos que se autorizan bajo el contrato que el nuevo género propone sean susceptibles de lecturas también ambiguas. Estas, a diferencia de las recepciones más "tradicionales" en las disciplinas "científicas", sacan a la luz abiertamente el carácter político de los textos, un carácter que solo se manifiesta de forma implícita en algunos de los discursos literarios, históricos y etnográficos a los que se asimilan.

En este artículo me propongo reflexionar sobre estas condiciones de recepción a partir de los procesos de interpretación que afectaron la polémica más difundida en torno al género testimonio: la que enfrentó a Rigoberta Menchú --protagonista e informante del volumen de Elizabeth Burgos Me llamo Rigoberta Menchú y así me nació la conciencia (1983) -- y al antropólogo David Stoll, autor del volumen Rigoberta Menchú and the Story of All Poor Guatemalans (1999). No pretendo añadir más leña a una polémica que ya ha llenado hojas de reflexiones y argumentos sino utilizarla como marco para la reflexión sobre cómo los vínculos entre autoría, autoridad y verdad se entretejen en torno al género testimonio, pero también cómo afectan a textos pretendidamente científicos o más documentales como el de David Stoll. Mi artículo puede servir, así mismo, como síntesis bibliográfica para aquellos que quieran acercarse a esta controversia y conocer algunos de los principales argumentos que en ella se contrapusieron.

La autoría es siempre una proyección de la obra: construcción de una enunciación implícita, que suele nominarse en el paratexto de la misma. Sin embargo, y pese al acta de defunción del autor que

\footnotetext{
${ }^{1} \mathrm{O}$, como dice Miguel Barnet: "Las imágenes y los personajes puestos a jugar en el género de la novela-testimonio pretenden mostrar los aspectos ontológicos de la historia, los procesos sociales y sus dinámicas internas; estudiar los casos individuales en función de los patrones de conducta colectivos, y dar claves eficaces e imparciales para la interpretación de la historia social y no para su burda descripción, como ha sido usual en los manuales extraídos de los viejos y apolillados archivos de las tendenciosas cabezas de los etnólogos e historiadores del pasado" (1998[1981]: 48-49).
} 
pretendió certificar Roland Barthes en 1968, tiene también siempre una dimensión extratextual, en tanto que los autores son también personajes públicos que se sitúan en posiciones política y culturalmente determinadas. Ambas dimensiones --textual y extratextual-- resultan complejas en el caso de aquellos testimonios que, como el de Menchú, son fruto de la colaboración entre dos sujetos que asumen de manera variable su responsabilidad sobre el texto. Por este motivo, para identificar las instancias entre las que se produce la polémica que nos ocupa hay que tener en cuenta que tanto David Stoll como Rigoberta Menchú y Elizabeth Burgos intervienen en ella desde posiciones a menudo ambiguas y cambiantes. En líneas generales, Stoll habla desde la ambigüedad causada por la apariencia neutral de unos argumentos que, sin embargo, contribuyen a una determinada posición política en un debate cultural en curso en el contexto de los Estados Unidos de finales de siglo XX. Al mismo tiempo, el cambio en la filiación política y en la popularidad de las dos implicadas en la constitución del testimonio produce una diferencia notable entre los argumentos que mantuvieron en la fecha de redacción del libro y los que hacen públicos a finales de la década de los noventa. En este artículo me propongo analizar estas diferentes posiciones haciendo especial mención a los modos de autorización y representación que el antropólogo critica a la Nobel, y a los que él mismo utiliza para presentar como real su propio relato. Me situaré en el marco crítico que permite la ubicación genérica "testimonio" como espacio flexible e interdisciplinario necesario para reflexionar sobre cómo se han utilizado conceptos como "autoridad", "autenticidad" o "representación" en la interpretación de los textos entre los que se mantiene la polémica.

\section{Autoridad, autenticidad y representación}

Existe un género que sirve para dar testimonio de la voz y las impresiones, a veces politizadas de esta entidad indefinible y ambigua que hay quien insiste en denominar "el pueblo" que ha sido desvinculado del canon literario todavía con más insistencia que el testimonio. Se trata de los chistes, esos relatos breves, de origen y difusión oral que perviven durante más o menos tiempo en la memoria colectiva, y cuyos argumentos a menudo critican un determinado estado de cosas, o se refieren a acontecimientos o personajes públicos que han causado impacto en un momento concreto de la historia. Quizás el lector recordará haber reído con chistes sobre el presidente o el ministro de turno, o haber fruncido el cejo ante un chiste que le parecía misógino o xenófobo. Existen también esos chistes que nos dejan con una sonrisa helada en la boca o con una exclamación que sustituye la imposibilidad de reír. Todos estos distintos tipos de chistes se hicieron sobre la figura de Rigoberta Menchú en el contexto de Guatemala cuando se le concedió el premio Nobel de la Paz el año 1992. Me parece representativo uno que me tomo la libertad de transcribir. Dice así y, para entenderlo bien, hay que ponerlo en la boca de un guatemalteco: "La Mattel ha decidido hacer una muñeca de Rigoberta Menchú, para aprovechar el tema 
Mercé Picornell. Autoría, autoridad y verdad...

del Nobel. Dicen que Barbie y Ken están muy contentos, ya que ahora, además de casa, coche y gimnasio, por fin tendrán sirvienta". ${ }^{2}$

Se trata, sin duda alguna, de un chiste, por lo menos, misógino y racista. De todos modos, a lo mejor por esta misma "mala idea" que podemos intuir en su formulación, es orientativo de las muchas y diversas cosas que podía significar, en el contexto de Guatemala, la concesión del premio a una indígena como Menchú, quien, hasta después de este acontecimiento, no era tan conocida en su país de origen como pudiera parecer a nivel internacional. ${ }^{3}$ La ironía de este chiste, podemos preguntarnos, ¿es sobre el personaje de Rigoberta? ¿Afecta a los indígenas a quienes de alguna forma representa? ¿Puede ser una crítica al sistema que utiliza en su propio beneficio a los indígenas que puede asimilar? Personalmente, solo la última opción me parece mínimamente ocurrente y significativa de algunas cuestiones que afectan la conversión en polémica de la figura de Menchú y, sobre todo, de su testimonio mediado y transcrito por Elizabeth Burgos.

Sin intención de explicar un chiste tan sencillo, sí que creo que vale la pena fijar la atención en cómo ironiza sobre dos aspectos esenciales: primero de todo, sobre la importancia pública e internacional de la distinción que ha recibido la figura de Menchú; en segundo lugar, sobre la posibilidad de apropiación de una figura de éxito por el sistema al cual teóricamente ésta critica. Desde esta doble intención, puede ser releído como la crítica a un sistema que decide qué subalternos pueden ser asimilados y los términos en los cuales lo serán. Así entendido, nos puede hacer pensar en la inocencia relativa con la que el "pueblo" de Guatemala o, si se prefiere, los "indígenas" de Guatemala, recibieron la noticia del Nobel, un premio que, si bien ubicaba en el mapa occidental el conflicto de este país (y a una indígena en las portadas de muchos periódicos), no tenía por qué suponer ningún descubrimiento en el país de origen de Menchú. Con este comentario, no pretendo quitar importancia a la concesión del Nobel, un premio simbólico en un año tan proclive a los descubrimientos y a las inauguraciones como lo fue el 1992. Mi reflexión va más en el sentido del comentario de Eduardo Galeano cuando, en el seno de las diversas polémicas sobre la adecuación de dar un premio como el Nobel a una persona como

\footnotetext{
${ }^{2}$ Cita el chiste Stephen Benz (1996: 26) junto con otros que bromean sobre la condición de Menchú en el contexto al que se tuvo que desplazar para que le dieran el premio, siendo, de todos modos, una indígena, una mujer y también una especie de 'guerrillera' de apariencia inofensiva y que no habla muy bien en castellano. Dice así otro chiste: "Rigoberta llegó al aeropuerto de Noruega para asistir a la entrega del premio Nobel, y el guarda le tocó la bolsa de su blusa y le dijo '¿Qué lleva ahí?' Ella le dijo: ‘misiles'. El guardia inmediatamente llama a todos los policías y llegan todos corriendo con sus pistolas, cuando le preguntan de nuevo, ¿qué lleva ahí? Dice Rigoberta: ‘mis hiles, mis tijeres, mis agujes...” (1996: 26).

${ }^{3}$ Así parecen querer dejarlo claro David Stoll pero también, desde una opción crítica opuesta, Arturo Arias (1996: 29-47).
} 
Menchú ${ }^{4}$, comenta que cabría invertir los términos de la reflexión y empezar a pensar si el premio Nobel es lo bastante importante para la guatemalteca, si es que con ella, como explica la introducción de Burgos a su testimonio, pretendemos simbolizar el sufrimiento de "todos los indígenas americanos". ${ }^{5}$

Dice así el prólogo de Burgos a la primera edición de la biografía de Menchú, con una voluntad de representación que ha sido criticada por la amplitud con la que se propone y por el esencialismo que encubre:

Rigoberta Menchú tiene veintitrés años. Se expresó en español, lengua que domina desde hace solo tres años. La historia de su vida es más que un testimonio sobre la historia contemporánea que sobre la de Guatemala. Por ello es ejemplar, puesto que encarna la vida de todos los indios del continente americano. Lo que ella dice a propósito de su vida, de su relación con la naturaleza, de la vida, la muerte, la comunidad, lo encontramos igualmente entre los indios norteamericanos, los de América central y los de Sudamérica. Por otro lado, la discriminación cultural que sufre es la misma que padecen todos los indios del continente desde su descubrimiento. Por la boca de Rigoberta Menchú se expresan actualmente los vencidos de la conquista española. (1983: 9. El subrayado es mío).

Y en boca de Menchú en el primer párrafo del libro: "Mi situación personal engloba toda la realidad de un pueblo" (1983: 21). De hecho, se trata de una fórmula de proyección social del relato biográfico individual que podemos encontrar en las primeras líneas de muchos otros testimonios. En el caso del relato de Menchú se ve incrementado por una voluntad más clara de convertirla en estereotipo, voluntad que se refleja en la proyección de la imagen de Menchú como la indígena "auténtica, comprometida y consciente" cuya voz se ha "rescatado" para transmitir una justa reivindicación política. En general, como ya argumentó en su momento Doris Sommer (1988), es en la asunción de esta representatividad del testigo respecto a $s u$ colectivo que se basa el contrato de lectura de este tipo de

\footnotetext{
${ }^{4}$ Y no solo indígena, sinó también con las manos manchadas, si no de sangre, sí de la gasolina de haber preparado algún que otro cóctel molotov de estar por casa, según dice David Stoll (1999a: 213) para criminalizar a la guatemalteca. De sangre, sí que las han tenido otros Nobel "de la paz". Sin pretensión de exhaustividad, podríamos nombrar los presidentes norteamericanos Theodor Roosevelt (1906) --que había sido corresponsable de un millón de muertes civiles poco antes en la Guerra de Filipinas (1899-1902)-- o el belicista Woodrow Wilson (1919) que implicó a su país en la I Guerra Mundial, el primer ministro israelí Mehahen Beguin, que había sido dirigente máximo del grupo terrorista Irgun Zvai de Deir Yassin en 1948, en un premio que compartió con el dictador militar egipcio Muhammad Anwar El-Sadat. Por no hablar de casos como el de Henry Kissinguer (1973), apoyo de dictadores sanguinarios como Augusto Pinochet, en su época como secretario de estado de Richard M. Nixon y tan responsable de haber puesto fin a la participación norteamericana en la Guerra de Vietnam como de incrementarla en 1969. El premio concedido al presidente Barack Obama (2009), solo nueve meses después de su toma de posesión, le acompañaría para manchárselas después con la intervención en Libia (2011) y el sostenimiento de la guerra en Afganistán hasta el presente.

${ }^{5}$ Dice textualmente Galeano:" El Nobel de la Paz, que Rigoberta ganó en el 92, no sólo fue la única conmemoración decente y justa de los 500 años de eso que llaman Descubrimiento de América, sino que, además, resultó un buen plumerazo para un premio que necesitaba limpieza. [...] Patas arriba: el mundo al revés discute ahora si Rigoberta merecía ese premio, en lugar de discutir si ese premio la merecía.”
} 
discursos. Este contrato es reforzado por la presencia del mediador, instancia narrativa que asume el papel de facilitador del relato del testigo (o, si se prefiere, en términos antropológicos, del informante) cuya voz "auténtica" nos pone al alcance. Si se me permite el juego de palabras, podríamos describir el procedimiento de este contrato afirmando que el mediador re-presenta la voz del informante (es decir, la vuelve a presentar, modificada y transcrita) y que, a su vez, este representa políticamente la experiencia de un colectivo que hasta el momento no se ha podido expresar públicamente en los canales de difusión internacional.

Los distintos agentes que se relacionan en estos dos usos del verbo "representar" nos pueden hacer intuir el carácter complejo de la constitución del relato testimonial, carácter que se esconde bajo la apariencia simple, monologada y en primera persona del relato (auto)biográfico. Una vez puesta en evidencia esta complejidad, decidir quién es el "autor" del testimonio se convierte en una cuestión con implicaciones políticas y que puede afectar a la misma "autenticidad" que el texto pretende. Implica preguntarnos, entre otras cosas, quién es el responsable de atribuir al relato de Menchú un sentido que se pueda proyectar al de "todos sus semejantes". ¿Es el subalterno que ha accedido a la enunciación en un género no condicionado por la hegemonía?, ¿es, en cambio, el intelectual-mediador encargado de dar forma a su voz y su experiencia de forma significativa para los lectores del texto? Y, en todo caso, ¿cuál es esta comunidad de lectores que debe identificar los pactos de verdad y el sentido del relato complejo e intercultural que todo testimonio mediado produce?

En concreto, la asignación de autoría al texto de Menchú fue variando en los últimos diez años desde su publicación, paralelamente al crecimiento de la popularidad de la Nobel. Como veremos al adentrarnos en la polémica desatada por el libro de Stoll, la ambigua atribución de autoría del relato testimonial sirve tanto a Menchú como a Burgos para esquivar responsabilidades y reinvindicar la "verdad" y el sentido de la parte de la obra que incluye su trabajo. Puede servir de ejemplo el modo como la atribución de representatividad a la figura de Menchú que hemos visto en el prólogo de Burgos a la primera edición del testimonio será reformulada en sus aportaciones posteriores a la publicación del libro de Stoll. Declara así Burgos el año 1999:

Me atrevería a decir que Rigoberta Menchú es una representante fidedigna de este mestizaje que comenzó en 1492 y que no ha cesado de dar sus frutos. Lo que me resultó más original del discurso de Rigoberta Menchú, fue, precisamente, la expresión de ese pensamiento mestizo que colocaba sus reivindicaciones específicas por encima de lo racial, su búsqueda de alianza con los ladinos y el empeño de vencer las barreras que impiden la coexistencia. (Burgos, 1999b: 30).

De la misma forma, la autoridad “incrementada” de Menchú a partir de 1992 le permitirá también a la Nobel reivindicar públicamente la verdad colectiva de su libro contra las mentiras que Stoll le 
atribuye. ${ }^{6}$ Y es que de la asignación de autoría sobre el texto también dependerá el pacto que permita que se presente ante el público lector como un relato auténtico en el doble sentido de la palabra: verdadero, opuesto a la mentira o la omisión del relato del poder sobre unos hechos pasados; pero también genuino, fruto del discurso oral de un individuo real y no aculturado. Esta doble condición es reforzada con estrategias textuales, como, por ejemplo, las huellas del discurso oral del informante mantenidas por el mediador en la edición del relato. Como bien ha notado, entre otros, Carmen Ochando (1998: 136) estas huellas --que podemos encontrar en forma de equivocaciones gramaticales, repeticiones, fórmulas expresivas propias del discurso oral o del lenguaje indígena, etc. -- funcionan como marcas textuales para la veredicción del testimonio. Paradójicamente, estas marcas de autentificación son fruto de la voluntad del mediador de crear un relato verosímil, un relato al que debe de dar la forma estética necesaria para que parezca más cercano, más inmediato y también más auténtico al oído de un lector normalmente occidental --o "occidentalizado"-- y distanciado de las experiencias que se narran. ${ }^{7}$

\section{Orígenes: una polémica... ¿académica?}

Las discusiones sobre la autoría, la autenticidad y la representación de los testimonios han llenado páginas y páginas en la crítica sobre el género. El interés crítico por un género aparentemente simple en cuanto a su elaboración literaria radica precisamente en la posibilidad de servir como campo de pruebas para la concreción de discusiones como las que se generan en torno a la posibilidad de expresión o representación subalterna. En el contexto norteamericano este interés se explica también, y muy especialmente, en el marco los debates que se producen en torno a la apertura del canon occidental que se propugna desde espacios académicos afines a la crítica postcolonial y los estudios culturales desde mediados los años ochenta. Obras como Teaching and Testimony. Rigoberta Menchú and the North American Classroom (Steven Benz, 1996) --manual sobre cómo utilizar el género testimonio, y especialmente el libro de Menchú, en aulas de los Estados Unidos-- pueden mostrar hasta qué punto se encarnó en esta obra la necesidad de un cambio de perspectiva en los planes de estudios de educación superior norteamericanos.

En concreto, el centro de la discusión sobre la apertura del canon fue la Universidad de Stanford, donde un amplio grupo de profesores y estudiantes se organizaron para proponer un cambio del

\footnotetext{
${ }^{6}$ Dice así en la entrevista publicada en El País a raíz del escándalo Menchú-Stoll: "No les puedo obligar a entender. Todo, para mí, lo que fue historia de mi comunidad es mi propia historia. No salí del aire, no soy un pajarito que viene de las montañas solito, de una pareja de padres aislados del mundo. Yo soy producto de una comunidad, y no solo la comunidad guatemalteca" (Menchú, 1999: 6-7).

${ }^{7}$ Sobre el papel del mediador en la elaboración del discurso subalterno como "auténtico" y "diferente", ver Picornell (2002 y 2003).
} 
Mercé Picornell. Autoría, autoridad y verdad...

currículum de las asignaturas referidas a la "cultura occidental". Reclamaban su apertura a escritores, historiadores y filósofos no necesariamente "blancos", hombres y heterosexuales. Sus demandas fueron escuchadas: el nuevo currículum que se aprobó el año 1988 incluía, entre otras lecturas recomendadas, Me llamo Rigoberta Menchú y así me nació la conciencia (Elisabeth Burgos). Durante este año y hasta los primeros noventa, se puede seguir en la prensa universitaria y no universitaria norteamericana un largo debate sobre la ruptura del canon y lo que se dio en llamar el movimiento de lo "políticamente correcto". ${ }^{8}$ Quizás sea interesante notar que es en este contexto de enfrentamiento político y académico que David Stoll cursa sus estudios de doctorado, precisamente en la universidad de Stanford.

Cuando Stoll tiene acceso al testimonio de Menchú, este ya es un objeto de polémica. Dicho de otro modo, ha dejado de ser el relato de un sujeto sobre su experiencia de la represión en Guatemala, para ser el símbolo de una discusión política en el contexto académico y político norteamericano. De hecho, antes de que Stoll lo hiciera, el conservador americano Dinesh D’Souza ya había utilizado políticamente el libro de Burgos (o de Menchú) como diana contra lo que consideraba agresiones a la libertad y a la calidad en la educación superior estadounidense. En su libro Illiberal Education (1991) toma el testimonio como ejemplo del bajo nivel de las "nuevas tradiciones" que se han introducido en los nuevos programas académicos. D’Souza, desde este momento, se convertirá en un autor de best sellers sobre actualidad y política cultural. Un simple paseo por los artículos de opinión de D’Souza aparecidos en publicaciones periódicas durante la década de los noventa pude hacernos intuir cual podía ser la opinión del escritor ante un relato como el de Menchú . ${ }^{9}$ D’Souza considera que su único mérito ha sido el de permitir a los nuevos integrismos "estalinistas" que invadían las universidades norteamericanas imponer su visión política cerrada contra la "libertad" de visiones que proveía el currículum de lecturas clásicas tradicional. Menchú, dice D’Souza, resulta "eminente" no porque haya elaborado una obra "inmortal" sino porque ofrece a los partidarios de una apertura del canon un modelo de víctima propicio a su voluntad de representación política. Opina D’Souza:

Undergraduates do not read about Rigoberta because she has written a great and immortal book, or performed a great deed, or invented something useful. She simply happened to be in the right place at the right time. She supports the historicist pedagogy of CIV advocates ["Cultures, Ideas, Values", la asignatura que sustituyó en Stanford a la de "Western Culture"] who believe, with Hegel and Marx, that being is historical and that history progresses toward a designated end, in this case the final emancipation of proletariat. (1991: 73).

\footnotetext{
${ }^{8}$ Para un análisis detallado de la polémica del conflicto centrado en la universidad de Stanford ver Leigh Binford (2001).

${ }^{9}$ Para quien no conozca la obra de D'Souza, recomiendo una visita a su pàgina web (URL: www.dineshdsouza.com), donde se pueden encontrar artículos que dejan ver claramente su posición política ante cuestiones como las causas de la pobreza en el tercer mundo, la superioridad moral de Estados Unidos, o la justificación del apoyo de Estados Unidos a dictadores como Marcos o Pinochet.
} 
Ciertamente, la apropiación del testimonio de la Nobel por la academia norteamericana no es un acto altruista sin connotaciones políticas. ${ }^{10}$ Como han notado ya muchos estudiosos de los problemas de representación testimonial, la obra se convierte en una forma de acceso cómodo a la alteridad, una alteridad domesticada a partir de los moldes de lectura y de interpretación académicos y occidentales. ${ }^{11}$ No es este el uso que critica D'Souza. Tampoco tiene en cuenta que el cambio que proponen los intelectuales a los que ataca implica también un tipo diferente de apreciación del texto, una interpretación que tenga en cuenta la posición desde la que habla Menchú y el contexto político en el que toma importancia su discurso. Las justificaciones basadas en la calidad estética que arguye D’Souza no son relevantes para la nueva crítica cultural, interesada precisamente en el mismo criterio de elección que D’Souza denuncia: la dimensión política y cultural del relato objeto de estudio.

David Stoll utilizará argumentos bastante diferentes a los de D’Souza para desautorizar el relato de Menchú. La publicación de su libro Rigoberta Menchú and the Story of All Poor Guatemalans (1999a) desencadenó una larga discusión política y académica con posiciones similares a las del debate de Stanford, pero con la visión centrada en la persona de Rigoberta Menchú, ya reconocida internacionalmente gracias a la concesión del premio Nobel de la Paz. ${ }^{12}$ Pese a esta concreción en la figura de Menchú, la controversia Menchú-Stoll debe entenderse en un contexto político y académico

\footnotetext{
${ }^{10}$ Gayatri Spivak ha reflexionado ampliamente sobre las formas así como una determinada crítica radical procedente de Occidente utiliza los sujetos subalternos para recrearse. La soberanía del sujeto occidental, deshecha según las tesis postestructuralistas, se reafirmaría en la creación de un "otro" que es representado o, mejor dicho, construido como sujeto monolítico, definido (o esencializado) unívocamente desde su diferencia: "It is impossible for contemporary French intellectuals to imagine the kind of Power and Desire that would inhabit the unnamed subject of the Other of Europe. It is not only that everything they read, critical or uncritical, is caught within the debate of the production of that Other, supporting or critiquing the constitution of the Subject as Europe. It is also that, in the constitution of that Other of Europe, great care was taken to obliterate the textual ingredients with which such a subject could cathect, could occupy (invest?) its itinerary -not only by ideological and scientific production, but also by the institution of the law" (1988: 280).

${ }^{11}$ Resultan iluminadoras en este sentido las aportaciones de Robert Carr (1992) y Gareth Williams (1996).

${ }^{12}$ Resulta interesante en este sentido la reflexión de Edward F. Fischer (2001) sobre la compleja recepción del libro de Stoll en los entornos académicos americanos, donde su obra resultó polémica antes de ser publicada a causa de las consecuencias políticas que podría acarrear en la lucha por los derechos humanos de América Latina, cosa que, según Fischer, provocó que el libro fuese rechazado por múltiples editoriales.
} 
Mercé Picornell. Autoría, autoridad y verdad...

más amplio, donde el testimonio en cuestión ha sido apropiado e reinterpretado con diferentes voluntades políticas. ${ }^{13}$

\section{Un antropólogo poco inocente}

El libro de Stoll se plantea cómo el desarrollo de una tesis en apariencia sencilla: el relato de Menchú es falso, y el antropólogo, que ha llegado a esta conclusión a través de un trabajo de campo durante el cual ha realizado múltiples entrevistas, se ve en la obligación de sacarla a la luz, para desmitificar una lucha cuyo enaltecimiento perjudica a la población guatemalteca. Stoll se presenta al inicio del libro como un antropólogo comprometido que, como sus colegas que han trabajado en el entorno de América Central, conoce bien el libro de Burgos y lo ha leído sin cuestionar la fiabilidad de la mediadora ni de la informante. Es a partir de unas entrevistas realizadas en las poblaciones que son escenario del relato de Menchú que descubre algunas incoherencias entre el discurso de la Nobel y el de sus actuales informantes. El hilo de estas incoherencias lo conducirá, según explica en el primer capítulo, a descubrir toda una farsa que no impugna la denuncia del antropólogo contra el genocidio que se produjo en Guatemala durante las tres últimas décadas del siglo veinte, pero sí que supone una revisión sobre quiénes son los implicados en la masacre.

Según Stoll, la "farsa" de Menchú ha contribuido a difundir de una forma incorrecta la historia reciente de Guatemala y, sobretodo, a simplificar excesivamente las instancias que han intervenido en ella. El propósito sería loable si no fuese porque su neutralidad se ve a menudo puesta en entredicho. Desde las primeras páginas del libro, la inocencia primera de Stoll respecto a la historia de Menchú se debilita cuando nos damos cuenta de que lo que realmente mantiene la línea de su exposición es una determinada percepción sobre el papel de la guerrilla en Guatemala y su relación con los indígenas. Explica así la proyección de sus descubrimientos en las primeras páginas de su libro: “An unimportant discrepancy over how her brother died in Chajul, was the first sign of more significant one: the considerable gap between the voice of Revolutionary commitment incarnated by Rigoberta and the peasant voices I was listening to" (1999a: 10). Podemos notar en estas últimas líneas cómo la disidencia

\footnotetext{
${ }^{13}$ En la contraportada de la edición que manejo, por ejemplo, parece claro que el contexto del volumen el debate norteamericano sobre lo políticamente correcto y los debates sobre la identidad. Se destacan las siguientes afirmaciones de Charles Lane para The New Republic: "U.S. leftists who give his arguments a full hearing --and who have not been deafened by tehir own dogma-- will find Stoll's analysis difficult to dismiss" y de Kevin J. Kelley para Seven Days: "In this hotly debated new book, key points of which have been corraborated by The New York Times, David Stoll compares a cult text with local testimony from Rigoberta Menchú's home town. His reconstruction of her story goes to the heart of debates over political correctness and identity politics and provides a dramatic illustration of the rebirth of the sacred in the postmodern academy".

En esta última cita, sorprende la frivolidad con el que se desplaza un problema de justicia y derechos humanos en Centroamérica --la verdad o mentira sobre asesinatos y torturas-- hacia un marco académico y puramente norteamericano.
} 
"sin importancia" sobre cómo fue torturado el hermano de Menchú sirve también a Stoll para autorizarse como verdadero "escucha" de la palabra de los indígenas "auténticos", palabra que contrapone a la voz "revolucionaria" que encarna Menchú.

En artículos posteriores en defensa de su libro Stoll utilizará este mismo recurso testimonial de presentarse como la voz de los indígenas verdaderos, cuyo discurso ha sido ocultado por la versión omnipresente de Menchú. ${ }^{14}$ La tesis de fondo del libro de Stoll, por lo tanto, no versa sobre el libro de Menchú en sí, o sobre su misma conversión en emblema o representante de la lucha indígena. En realidad pretende elaborar una desmitificación más global sobre el papel de las guerrillas y sus relaciones con los indígenas, tema que debía resultar poco nuevo a Stoll si recordamos el título de la tesis doctoral que había publicado unos años antes: Between Two Armies in the Ixil Towns of Guatemala (1993). En esta, y también en su libro de 1999, Stoll parte de la base que los indígenas no acogieron la lucha de guerrillas por propia voluntad, como parece afirmar el libro de Menchú, sino coaccionados por el terror que los disidentes del gobierno de Guatemala les causaban. ${ }^{15}$ Según explica Arturo Arias (2002), la relación entre los indígenas y la guerrilla fue un tema de debate dentro del EGP (Ejército Guerrillero de los Pobres) y que llegó a ocasionar una ruptura en el seno de la organización. Arias explica la polémica entre estas posiciones para argumentar que Stoll la discute conociendo más los intereses y la bibliografía norteamericanos que la producción historiográfica y el debate político guatemalteco sobre el tema. ${ }^{16}$

\footnotetext{
${ }^{14}$ Dice así en un articulo traducido en la revista Lateral: "Me cuesta creer que en nombre de la defensa del pueblo maya se quiera prescindir de otras versiones de la misma historia. Precisamente por la atención despertada por Rigoberta me parece indispensable incluir a los supervivientes de la violencia, ixiles y quichés que no están al servicio del ejército ni de la guerrilla, cuyas versiones de los hechos tienen el mismo derecho a ser escuchadas" (1999b: 32).

${ }^{15}$ Se invierte así el sentido de la "toma de conciencia" que mueve el título del testimonio de Menchú: “The conscious-raising that looms so large in I, Rigoberta Menchú provides part of the answer. The very idea of 'raising' consciousness is wielded by the movement dissatisfied with the prevailing level of insight. Scholars have long debated whether peasants are ideologically committed to the insurgencies that sweep them up. They might instead be opportunistic, coerced or desperate -with some in each of the four camps. In Guatemala the most obvious feature of survivor testimony is not ideological conversion. Instead it is terror, especially but not exclusively of the army" (1999a: 191).

${ }^{16}$ Dice Arias: "If we are to believe Stoll's bibliography, he was familiar with the documents in Spanish published since the 1970 's. Why, then, did he present his subject-mater as he did? In his reductive reading, he exploits Americans' tradition ignorance of Guatemalan affairs and sells a hoax to a non-specialized audience. He implies that Menchú might still secretly be a member of the EGP, that the Guatemalan left still looks or thinks as it did in the early 1980's. Thus, he can claim to have a) unmasked Menchú as an EGP member; b) exposed the falsehood of the EGP and, by extension, of the URNG and of the guerrilla strategy in this broadest sense; c) explained to both Americans and Guatemalans (who in his portrayal never understood their own history) where the latter had gone wrong; and, d) finally, and possibly most rewarding for him, proved wrong the US's own intellectual left and their soapy portrayal of Menchú as a 'pobrecita' woman of colour. Unfortunately, in this scheme of things he did not count on one factor: just as neither Menchú nor the EGP could ever hide their own past, neither could he hide Guatemala's political history, the story of its revolutionary left, and the academic paper trail that documents both" (2002: 501).
} 
Debo confesar que la complejidad de la cuestión supera mis conocimientos sobre el contexto centroamericano de la segunda mitad del siglo veinte, o sobre las polémicas entre los estudiosos sociales y politólogos guatemaltecos o que se interesaban por la zona. Sin entrar necesariamente en este debate, sin embargo, sí que me parece que puede ser relevante revisar la exposición de Stoll desde el punto de vista de que también su argumentación utiliza determinados procedimientos de autorización para sostener una posición política no siempre explícita. Desde el momento en que se basa en la experiencia para fundamentar una tesis política, el libro de Stoll es, en cierta medida, un texto "testimonial", aunque se pretenda contra los procedimientos que ha institucionalizado el género latinoamericano. Esta presencia testimonial se distribuye a lo largo de las cuatro partes principales del libro. Las dos primeras partes tienen una apariencia más documental, de recogida de informaciones y contraste con el testimonio de Menchú. En la mitad del libro, la "demostración” de la escolarización de Menchú es un punto álgido en la exposición de Stoll, ya que con ella se hace explícita la condición de "mentirosa" de la indígena y, en consecuencia, también la farsa que supone su testimonio mediado, autorizado como el discurso oral de una joven guatemalteca que teóricamente no sabe escribir. ${ }^{17}$ En los capítulos que siguen, Stoll se dedicará más intensamente a analizar cómo se crea el "personaje” de Rigoberta Menchú y cómo evoluciona su funcionalidad política. Veamos con más detalle cómo se construye la argumentación de Stoll para analizar posteriormente cómo se han intentado refutar sus tesis.

El capítulo que inicia el libro está centrado en el personaje de Vicente Menchú, el padre de la Nobel, y en su pueblo, Chimel. Aquí empiezan a notarse las implicaciones políticas del argumento del antropólogo. Parte de la suposición que los indígenas de Guatemala, por lo menos los de la zona del Quiché que habitaba la familia de Menchú, no tenían motivos para enfrentarse con unos ladinos que no les dominaban, sino que convivían con ellos, que a menudo eran más pobres que los mismos indígenas. Según Stoll, estos, entre los cuales el padre de Menchú, estaban más preocupados disputando entre ellos las propiedades de las tierras que habitaban que no pensando en luchar contra un sistema que

\footnotetext{
${ }^{17}$ El hecho que Menchú asistiera a un colegio de monjas belgas ha sido uno de los polos del ataque a la Nobel, quien responde la cuestión afirmando: "Se les olvidó preguntar qué hacía [en el colegio]. Era sirvienta. Yo ganaba 12 quetzales al mes trabajando en el colegio. Uno se lo daban al Instituto del Seguro Social, y recibía en efectivo 11. Es otra parte de mi vida que no conté en mi libro porque lo que menos hubiera querido en esos años es asociar el belga conmigo, porque un programa de las hermanas llevaba a las señoritas [estudiantes], por supuesto de familias muy acomodadas, a hacer un trabajo de campo, que era vivir dos o tres días en una comunidad, conocer a gente, la sensación de un pueblo capitalino, y así se completaba la educación. Muchas de esas señoritas han muerto. Tenían otros conventos que fueron destruidos totalmente [...] Teníamos dos clases por semana, tres horas cada día, a partir de las tres de la tarde. No estudiábamos con el resto de las alumnas, teníamos una maestra contratada para que nos diera alfabetización; después, costura y cocina, los sábados y los domingos. Lo llamaban educación para el hogar. Nuestra obligación era limpiar antes de la alfabetización y, después de eso, limpiar hasta las once de la noche" (1999: 6).
} 
teóricamente les oprimía. ${ }^{18}$ En estos capítulos iniciales, Stoll defiende que Menchú, a partir del enaltecimiento político de la figura de su padre, transforma un problema de tierras entre indígenas en una falsa dicotomía entre éstos y los "blancos". Es muy posible que la exposición de Menchú incurra en simplificaciones al plantear una lucha cuyas causas y consecuencias pueden ser bien complejas si entendemos que intervienen en ellas de una u otra forma guerrilleros, indígenas, propietarios ladinos y el ejército, pero también la CIA y los directivos de la multinacional "United Fruit", bastante "preocupada" también, como los indígenas que describe Stoll, por la propiedad de las tierras de cultivo en Guatemala. Según Stoll, la visión heroica de los indígenas y guerrilleros que propone Menchú nos ciega ante la posibilidad de entender la historia "real" de la zona antes que llegasen las guerrillas. En la narración de Stoll los indígenas ven a los guerrilleros con miedo y no creen en su discurso. Se trata de hombres armados, como los del ejército, y cómo estos pueden ser peligrosos. El antropólogo llega a la conclusión que fue con su aparición que empieza realmente el "conflicto" y desde esta base revisa algunas de las escenas principales en el relato de Menchú.

Del testimonio de la Nobel rebate sobre todo dos escenas: la de la muerte de su hermano Petrocinio, torturado y quemado vivo en la plaza pública del pueblo, y la de la masacre producida en la embajada española en Guatemala, donde murió el padre de Rigoberta Menchú. Stoll utiliza distintas fuentes orales para argumentar que en la plaza de Chimel no quemaron a nadie (aunque sí lo hicieron en poblaciones vecinas). Sugiere, con medios semejantes, que de hecho, la entrada en acción del ejército en la embajada española no fue lo que causó la muerte de todos sus ocupantes sino que puede que se tratara de una inmolación programada por algunos guerrilleros a escondidas de los indígenas y estudiantes que habían participado en la acción. ${ }^{19}$

Revisado el papel de la guerrilla, Stoll dedica el tercer capítulo a demostrar cómo Menchú, durante los años en que afirma en su testimonio haber presenciado de alguna forma todos estos hechos, estaba siendo escolarizada con unas monjas católicas, lejos de su población de origen. Stoll afirma que hasta los diecinueve años ella no volvió a su pueblo, donde fue recibida como una extraña, y que no es hasta el año 1981 que se implicará realmente en la lucha de la guerrilla, a causa de un encuentro en México con sus hermanas pequeñas, mucho más comprometidas que ella misma. Aunque no tuviese experiencia política, Menchú era para los guerrilleros una buena figura para atraer a los medios de solidaridad internacional.

\footnotetext{
${ }^{18}$ Resume así Stoll: "To summarize a complicated situation, five groups of Mayan peasants were competing for land in and around Chimel. First there was Vicente Menchú and the homesteaders of Chimel. Then the turns of Laguna Danta, who never stopped insisting on the validity of the defective title they had purchased; then a dissident faction with Vicente's group, lead by homesteaders from Parraxtut; then two other groups from the villages of Los Canaques and Macalajau. Except for a few individuals from Los Canaques, all the claimants were indigenous" (1999a: 36).

${ }^{19}$ Argumentación que podía coincidir con la del gobierno guatemalteco de 1980. No pensaron los mismo los jueces que condenaron en enero de 2015 a cuarenta años de cárcel al jefe de policía responsable del operativo, Pedro García Arrendondo, por crímenes contra la humanidad, tras una causa judicial que se arrastró durante años y años.
} 
Era hija de un mártir y lo bastante independiente hasta el momento para poder convertirse en la representante pública del Frente Popular 31 de Enero, plataforma que integraba diversas entidades de guerrilleros, estudiantes, exiliados, etc.

La lectura de este tercer capítulo, además de rebatir la "romantización" de las guerrillas que han causado ciertos testimonios, explica algunos de los aspectos sobre la redacción de Me llamo Rigoberta Menchú y así me nació la conciencia, en los que no se han fijado las aproximaciones más cercanas a la crítica literaria. Como veremos, Stoll hace referencia sobre todo a la parte más oscura del proceso de difusión del testimonio, la de los enfrentamientos entre Menchú y Burgos desde el momento en que la indígena es famosa. Lejos de discutir los contratos de lectura y representación que el testimonio propone, el antropólogo atribuye a Menchú la autoría plena del libro. Afirma que ha escuchado algunas de las grabaciones que hizo Burgos y que estas demuestran que la transcripción de la antropóloga fue lo bastante literal para que la responsabilidad del libro --y, en consecuencia, de sus mentiras-- recaigan sobre Menchú. Stoll cita incluso casos de relatos de lucha de Rigoberta publicados anteriormente en forma de panfletos que se difundieron en Guatemala, para justificar que Menchú "dictó” a Burgos su historia de vida desde una posición previamente tomada.

En declaraciones posteriores a la publicación del libro de Stoll, Burgos establece una posición ambigua respecto a esta cuestión. Explica que, siguiendo las enseñanzas de George Devereux, procedió a programar la entrevista partiendo de un enfoque no intrusivo. ${ }^{20}$ Esta forma de entrevista da fuerza a la impresión de Stoll sobre la no intervención de Burgos en el relato de la Nobel. Su fuerza se deshace, sin embargo, si atendemos al modo en que la antropóloga dice que dio forma al libro:

Tras la transcripción de los casetes, eliminé las preguntas, como suelo proceder cuando realizo una entrevista. Comencé elaborando fichas temáticas y señalando la página en que cada tema aparecía en el manuscrito. Más tarde buscaba la página, recortaba, iba ensamblando y, de este modo, fui armando el libro: lo que ahora se hace con el cortar y pegar del ordenador. Una vez establecida la estructura a partir del ensamblaje de temas, procedí a la tarea del enhebrado, que consiste en buscar las perlas raras, aquellas frases o palabras rezagadas, perdidas en medio de los desechos que se eliminan para que el lenguaje hablado continúe transmitiendo una voz y, al mismo tiempo, sea legible; es decir, que no aburra, que se lea como una novela. $(1999: 20)^{21}$

La cuestión se complica un poco más si añadimos todavía más voces a este entramado de modificaciones sobre el relato. De hecho, Arturo Taracena, el representante del EGP en Europa que

\footnotetext{
20 “Consideraba que el entrevistador debía intervenir lo menos posible, las preguntas debían servir para inducir el advenimiento de la palabra del entrevistado, se tenía que dejar libre curso al inconsciente, es decir, a la asociación libre y respetar los silencios hasta que la persona entrevistada los interrumpiera" (1999: 20).

${ }^{21}$ Cabe decir que el proyecto inicial no era hacer un libro, sino una entrevista periodística que se publicó al final en la revista Le Nouvel Observateur con el título "Guatemala: voyage au bout de l'horreur" en el número del 24 de abril de 1982, pp. 130-146.
} 
Mercé Picornell. Autoría, autoridad y verdad...

puso en contacto a Menchú con Burgos, declaró en un reportaje de Peter Canby para The New York Review of Books que intervino en las entrevistas y también en la edición del libro, aunque Burgos "borró" su presencia en la primera edición del libro:

Cécile Rousseau y yo le presentamos a Rigoberta a Burgos. En ese momento, Burgos no sabía nada sobre Guatemala. Planteamos la agenda junto con ella y participamos los dos primeros días en las entrevistas. Nos marchamos el tercer día sólo porque pudimos darnos cuenta de que todo iba muy bien. Al final de la semana, regresé al apartamento de Burgos y recogí a Rigoberta Más tarde, cuando el manuscrito estuvo listo, lo edité, uní los temas e hice algunos cambios en los hechos y en la gramática. Hice un glosario de palabras guatemaltecas y sugerencias para los cortes de los capítulos. (Canby 1999: s.p.)

Sin embargo, Stoll no tiene en cuenta el papel de Burgos o de la organización que tutelaba a Menchú en la composición del relato. Según el antropólogo, Rigoberta Menchú utiliza el testimonio para crear una identidad adecuada para ella: una "persona" o máscara que pueda representar a "cualquier mujer de Guatemala” y que debe ser, además, "auténticamente indígena”. Según Stoll, el esencialismo implícito a este planteamiento no responde ni a una semejanza con los procesos de representación etnográfica que conocía Burgos, ni a una estrategia del colectivo al que representa Menchú, dice así:

If Rigoberta's denial of Spanish and literacy was a preemptive defense of her authenticity, brought on by racist assumptions she was encountering, then the obsessive quality of these denials suggests that she was not just doing it for her listeners. She also could have been doing it for herself. The noble savage was invented by Europeans, but it has been taken to heart by many an indigenous intellectual seeking to join the wider world on equal terms. (1999a: 195)

El texto de Rigoberta Menchú además de mentir propone, según Stoll, la creación de un personaje ficticio: el del "indígena auténtico" comprometido con una lucha política. Ciertamente, bajo la voluntad representativa de Menchú se construye una identidad esencialista y estereotipada no muy lejana a la que podían poner en circulación los indigenismos tradicionales en cuanto a su forma, aunque pueda resultar muy diferente en cuanto a su funcionalidad política. ${ }^{22}$ Esta insistencia en la representatividad y autenticidad del indígena es construida en el relato de Menchú, pero sobretodo, en el entorno paratextual de la obra, del que no pudo ser responsable única la guatemalteca. Las descripciones que hace Burgos de Menchú han sido citadas recursivamente como muestra de este estereotipo. En distintos momentos del prólogo a la primera edición podemos encontrar imágenes de la caracterización tópica del buen salvaje --infantil, inocente, afable y movido casi instintivamente hacia las tareas de su tradición. Dice así en una descripción de Menchú que ha sido reiteradamente citada: "Lo que me sorprendió a primera vista fue su sonrisa franca y casi infantil. Su cara redonda tenía forma de luna llena. Su mirada

${ }^{22}$ Desde la crítica reciente del testimonio se ha notado que, en cierta forma, el testimonio mantiene el mecanismo de alterización de las representaciones tradicionales del indígena, es, como dice Elzbieta Sklodowska (1992 y 1993) apropiándose de la terminología de Michel de Certeau, un discurso heterológico. 
franca era la de un niño, con labios siempre dispuestos a sonreír [...] Sus gestos eran suaves y delicados" (1983: 12). Y en otro momento todavía más citado:

Por la mañana, un reflejo milenario impulsaba a Rigoberta a preparar la masa y a cocer las tortillas para el desayuno, y lo mismo al mediodía y a la noche. Verla trabajar me producía un placer inmenso. Como por milagro, en unos segundos salían de sus manos tortillas tan delgadas como una tela y perfectamente redondas... (1983: 13)

La desafortunada descripción del "placer" de Burgos viendo trabajar Menchú por un instinto "milenario" le ha valido críticas más o menos extremas en las que la relación que se establece en este fragmento es tratada como la muestra de un tipo de vínculo entre mediador e informante que es necesariamente jerárquico y de dependencia. ${ }^{23}$ Sin necesidad de ir tan lejos, las huellas de la conversión en símbolo auténtico del personaje de Menchú pueden mostrar el reverso negativo de toda estrategia esencialista, estrategia que deja de tener sentido cuando no aporta un rendimiento claro a su función política.

Stoll, sin embargo, no critica este esencialismo como algo que reduzca la necesaria heterogeneidad de la identidad indígena a un solo modelo para el uso de Occidente, sino el uso político que hace de él la lucha que Menchú promueve. De hecho, él mismo utiliza este procedimiento algo simplista de representación al proyectar la "falsedad" de la Nobel (es decir, su mentira y su falta de autenticidad) a la de todos los indígenas que simpatizan con la guerrilla. Así, a lo largo de su estudio, Stoll intenta desautorizar paralelamente el papel de Rigoberta Menchú y el de su lucha, estableciendo relaciones entre la verdad del testimonio de la Nobel y las motivaciones de los guerrilleros a los cuales había representado. Lo hace en una exposición que toma, como el testimonio, una forma híbrida, entre el relato de investigación antropológica, la interpretación política y la crónica periodística. Quizás por este motivo, la polémica que causó --más que entre Stoll y Menchú, entre el antropólogo y los defensores del testimonio-- supone, en el fondo, un juego bastante tendencioso entre formas de leer y autentificar un texto y los fenómenos que lo rodean en un contexto cargado políticamente, donde cualquier toma de partido tiene implicaciones políticas que no se pueden ignorar.

\footnotetext{
${ }^{23}$ Otros momentos menos citados en este prólogo son también interesantes para entender el sentido que le otorga al testimonio Burgos. Dice explicando el hecho de que la entrevista se realizará en castellano y no en la lengua de Menchú: "La palabra es su única arma: por eso se decide a aprender español, saliendo del enclaustramiento lingǘstico en el que los indios se han parapetado voluntariamente para preservar su cultura" (1983: 9). Me parece bastante cínico hablar de "enclaustramiento" para definir la opción de un grupo de utilizar su propia lengua. La estrategia de Menchú cuando aprende castellano es clara y demuestra quién es el destinatario de la obra: el público occidental a quien quiere dar a conocer una situación de opresión y genocidio. Un objetivo tan claro muestra -en palabras de Burgos, "una voluntad manifiesta de ser parte activa de la historia"- supone, según la antropólogo, el hecho de que Rigoberta Menchú posee "un pensamiento muy moderno" (1983: 11), lo que la desvincularía de otras luchas indígenas más enraizadas en los referentes culturales del pasado precolombino.
} 


\section{Recepción y ambigüedad: el margen interdisciplinario como excusa}

Estas implicaciones políticas produjeron, en el caso de la publicación del libro de Stoll, una difusión tan amplia que se llegó a plantear la posibilidad de retirar el premio a Menchú. La publicación del libro de Stoll fue recibida por la prensa de los Estados Unidos con titulares sensacionalistas del tipo "Nobel Prize Winner Accused of Stretching Truth", en la primera página del New York Times, "When the Facts Stood in the Way of Crusade", del Washington Post, incluso más atrevidos, como el del $U$. S. News \& World Report, "Nobel Prize for Fiction?", o directamente en el Reader's Digest "Not the Whole Truth!”. El New York Times publicó el 17 de diciembre de 1998 un reportaje de Larry Rother donde el periodista comprobaba las supuestas "mentiras" de Menchú despojándolas todavía más del contexto de producción del libro y del sentido colectivo que pretendía su historia. Este reportaje fue todavía más leído que el libro de Stoll, y contribuyó a que la dimensión histórica y política que la polémica encierra fuera reducida a una cuestión sobre la veracidad de las palabras de Menchú. Puede ser interesante notar también que este escándalo mediático se produce tan sólo siete meses después de la presentación del informe de la Guatemala Nunca Más, coordinado por Juan Gerardi, obispo auxiliar de Guatemala, asesinado dos días después de la presentación del trabajo. ${ }^{24}$ Las acusaciones a Menchú se hicieron extensivas rápidamente hacia todos aquellos académicos norteamericanos que habían incluido el libro de Menchú en el currículum de sus asignaturas, y que fueron instados a reconocer su "error". Las supuestas "mentiras" de Menchú fueron así descontextualizadas y proyectadas en el contexto político y académico norteamericano como una forma de desautorizar a aquellos que creían en la necesidad de una ruptura del canon tradicional. ${ }^{25}$

\footnotetext{
${ }^{24}$ Menchú utiliza el referente colectivo de este informe para defenderse: "Qué casualidad que se diga ahora, que Rigoberta miente, a secas. Entonces mintieron los 25.000 testigos que entrevistó monseñor Gerardi antes de su muerte [...], y que afirman y reafirman y requeteafirman lo mismo o más de lo que yo hablo en mi testimonio Me llamo Rigoberta Menchú. Qué casualidad que se diga que Rigoberta miente cuando la Comisión de Esclarecimiento Histórico ha recorrido las comunidades y ha encontrado no solo esa verdad, sino que ha podido contactarse con todos los delitos de lesa humanidad" (1999: 7).

Opina también Eduardo Galeano: "No tuvo la misma repercusión [que el libro de Stoll], por cierto, el voluminoso y documentado informe de la Iglesia, elaborado por la comisión que el obispo Gerardi presidió, y que fue difundido el año pasado, dos días antes de su asesinato. [...] El informe habla de la responsabilidad directa, la responsabilidad de los títeres pagados. Sobre la otra, la de los titiriteros pagantes, bien valdría la pena que los Estados Unidos enviaran a todos sus antropólogos, y The New York Times movilizara a su cuerpo entero de redacción, para investigar el asunto. Pero el Pentágono y la Casa Blanca bien pueden silbar y mirar para otro lado: los norteamericanos no tienen la más puta idea de dónde queda este país, Guatemala, de nombre pintoresco y difícil de pronunciar" (http://patriagrande.net/uruguay/eduardo.galeano/ escritos/disparen.sobre.rigoberta.htm).

${ }^{25}$ Ver por ejemplo la crónica titulada “Anthropologist Challenges Veracity of Multicultural Icon. But many professors say they will stand by Rigoberta Menchu's memoir”, elaborada por Robin Wilson para la edición de The Cronicle del 15 de Enero de 1999 (http://chronicle.com).
} 
Mercé Picornell. Autoría, autoridad y verdad...

Podemos pensar que una recepción como esta haría subir rápidamente el libro de Stoll en las listas de ventas, y situarlo en un lugar muy significado de los escaparates de las librerías norteamericanas. De todos modos, nos podemos preguntar, ¿en qué espacio en estos escaparates? ¿En la sección de antropología, como parece ser que se correspondería a la intención del autor? ¿En la de crítica cultural o pensamiento político? ¿En la de historia de América Latina? ¿O quizás "simplemente”, en la de crítica literaria? La cuestión de los géneros y de las disciplinas no deja de tener importancia ya que determinará la lectura de la obra y su contraste con el libro que critica. Sin embargo, en el momento de rebatir los argumentos de Stoll, esta ambigüedad no ha sido tratada, aunque la utilicen recursivamente los defensores y detractores de Menchú para determinar la validez de unas u otras lecturas de su testimonio. Se suele partir de la base que los dos textos que se contraponen en el seno de esta polémica "pertenecen" a distintos géneros, aunque, como veremos, comparten algunos procedimientos para autorizarse. De esta forma, distanciados, se hace difícil poner de lado el libro de Stoll con el de Menchú y Burgos para evaluar el grado de verdad de uno u otro texto. Es por este motivo que las acusaciones de Stoll han sido rebatidas con distintos argumentos, pero pocas veces con referencias documentales concretas. Algunas de estas pocas referencias aparecen en las aportaciones críticas de Arturo Arias y de Carol A. Smith, que contraponen a los datos de Stoll, más hechos o referencias a la bibliografía que el antropólogo obvia o cita sin profundizar en sus argumentos. ${ }^{26}$ Sin embargo, la mayoría de críticas a Stoll se refieren al "tipo de verdad" que pretende defender para contradecir los enunciados de la indígena. En este sentido se presenta, de hecho, el comunicado que emitió la Fundación Rigoberta Menchú en el momento en que empezó la polémica:

El testimonio de Rigoberta Menchú tiene el valor de constituir un relato no de un testigo, sino la vivencia de una protagonista y la interpretación de lo que vieron y lloraron sus ojos, lo que oyeron sus oídos y lo que a ellos les contaron. Ningún testimonio puede ser visto como un reportaje periodístico ni como la descripción neutral de una realidad ajena [...]. Ninguna de las supuestas inexactitudes, exageraciones u omisiones que se pretenden demostrar en el mencionado texto restan méritos ni debilitan la verdad del testimonio de Menchú. ${ }^{27}$

El comunicado es bastante ambiguo y se escuda en el género testimonio para relativizar la necesidad de verdad de los hechos que en él se describen. Ciertamente, la forma de autorizar la "verdad" de un texto depende altamente del pacto de lectura que propone el género en el que se presenta, si bien esa verdad necesita arraigarse de manera clara en los hechos documentados. De hecho, tanto Stoll como sus críticos juegan a reubicar genéricamente el texto de Menchú en función de las lecturas que sean más oportunas a sus propósitos. En la mayor parte de su argumentación, parece que Stoll lea el texto de

\footnotetext{
${ }^{26}$ Ver Arturo Arias (2002) y Carol A. Smith (1999).

${ }^{27}$ Citado en la introducción a una entrevista a Mary Louise Pratt sobre la polémica del libro de Menchú, publicada en el diario mexicano La Jornada con el título "Las críticas al libro de Menchú, para desaparecerlo de las aulas"
} 
Menchú como un documento que, aunque no sea realmente ni etnográfico ni histórico, supone una crónica interpretativa de los hechos pasados. No se trata de una "simple" historia de vida, sino de un testimonio político, explica Stoll sin establecer claramente las bases de esta oposición:

Anthropologists have long collected life histories from people. Ordinarily we do not dwell on whether the results are true or not. The very idea of refuting a life story sounds journalistic. More important is the narrator's perspective and what this tells about a culture. Aside from being a life story, however, I Rigoberta Menchú was a version of events with specific political objectives" (1999a: 11).

Y afirma hacia finales del libro: "Like other such works, Rigoberta's testimonio presents itself as an eyewitness account, therefore asks to be interpreted literally, which makes any suggestion to the contrary sounds like an ad hominem attack" (1999a: 226). Curiosamente, para Stoll parece más susceptible de una lectura alegórica un relato de vida etnográfico recogido por un investigador con propósitos científicos que no el testimonio de Menchú. Es así que lo lee como un texto documental aunque, en su crítica, acabe llegando a la conclusión de que no se trata más que de un mito, es decir, de un relato que no es verdad y que sirve como estrategia para fundamentar una voluntad de identidad colectiva determinada. Precisamente, esta lectura más alegórica es la que utilizan otros críticos para defender el valor del testimonio. Por ejemplo, hay quien hace referencia a cómo el trauma afecta el recuerdo y justifica las "verdades" a medias del testimonio de Menchú en el hecho de que se trata de un relato hecho desde una memoria herida y, por no por esto menos susceptible de verdad. ${ }^{28}$

Las aportaciones posteriores de Menchú para defender la "verdad" de su obra hacen referencia sobre todo al tipo de verdad que su testimonio afirma. Se trata, dice la Nobel, de una verdad colectiva, que toma sentido por las múltiples memorias que incluye en un solo relato y no por la referencialidad simple de una sola vivencia. ${ }^{29}$ De forma similar, se ha defendido a la indígena aduciendo que su concepto de verdad no puede ser el mismo que el de Stoll, por lo cual los dos relatos no se pueden equiparar en las formas en las que se proponen como referenciales. Deben ser leídos con ojos diferentes y en su diverso contexto cultural. Jan Rus resume así este argumento en la introducción del número de la revista Latin American Perspectives dedicado íntegramente a la polémica:

In addition to this self-conscious, external shaping of the narrative, however, anthropologists and literary scholars have also argued persuasively that the story-telling conventions that inform $I$,

\footnotetext{
${ }^{28}$ Para esta interpretación ver, entre otras, la argumentación de Leigh Gilmore (2001).

${ }^{29}$ Contesta así a la pregunta de Juan Jesús Aznárez ¿Tiene medios para apoyar la veracidad en su relato?”: “Lea el informe sobre la recuperación de la memoria histórica, que recoge la verdad de 25.000 víctimas en Guatemala. Y también basta con ir a Guateamala y pararse en una finca agroexportadora par ver cuántos niños trabajan en esas fincas cortando cañas. Son realidades espeluznantes que no son del pasado. No se trata de si usted cree en mi verdad o en la de otro, sencillamente estoy diciendo que tengo derecho a mi memoria como lo tiene mi gente” (Menchú 1999: 7).
} 
Mercé Picornell. Autoría, autoridad y verdad...

Rigoberta Menchú internally are not those of Western eyewitness accounts but instead typical of non-Western oral traditions. Among others, such conventions include the assumption of a collective or amalgamated identity by the storyteller in order to summarize a whole community's history, the creation of a 'golden' past before exploitation or colonialism, in order to show how bad things have become and to identify the causes of the deterioration, and the simplification of the order of events in order to clarify the story line. (Rus 1999: 8)

Esta proyección colectiva de la que habla Rus puede ser interpretada también como fundamento de la historia de vida en uso en ciencias sociales de cuyo modelo bebe de alguna forma el testimonio desde sus orígenes cubanos. Barbara Dröscher (2001) va un poco más lejos en la consideración de esta diferencia documental, y distingue entre dos tipos de racionalidad diferente que explicarían la distinta forma de concebir la verdad de Stoll y Menchú. La diferencia cultural entre los dos "autores" en la que se basa Dröscher, sin embargo, no es válida si entendemos que el texto de Menchú es en realidad un libro elaborado para denunciar unos acontecimientos a un público internacional. Podemos pensar, por lo tanto, que su "verdad" pudo ser también adaptada por Elizabeth Burgos para los lectores potenciales de la obra.

Más inmerso en la crítica testimonial, Georg Gugelberger (1999) critica a Stoll porque no tiene en cuenta que, en el momento de publicación de su libro, la crítica del género testimonio se encuentra en una fase de revisión de los fundamentos de autenticidad de los discursos que incluye. Parece extraño suponer que la ignorancia de Stoll respecto a la crítica del género testimonio no le permitiría leer un texto destinado, de todos modos, al gran público y a la difusión amplia. La cuestión no deja de ser contradictoria y afecta la dimensión teórica que rodea al género más allá de su voluntad política inicial. De hecho, el mismo Gugelberger (1991) había defendido ocho años antes que el testimonio era un género popular, creado en los márgenes de las instituciones dominantes, por lo cual parece contradictorio que sea necesario estar al día del panorama crítico que lo trata para leer adecuadamente un ejemplar.

En definitiva, para defender el testimonio de Rigoberta Menchú delante de las críticas referenciales del antropólogo David Stoll parece que una opción válida sea literaturizarlo, proponer lecturas más alegóricas, más creativas, pero también más ambiguas. En el fondo, se trata de utilizar la hibridez de la categoría testimonio para reinterpretar Me llamo Rigoberta Menchú desde una perspectiva más cercana a la literatura que no a la etnografía, género al cual pretenden ligarse las estrategias de autentificación del libro de David Stoll. El carácter fronterizo del género testimonio hacen posible este desplazamiento hacia la literatura para esquivar las críticas más referenciales. El acercamiento del texto de Burgos al ámbito de la literatura para alejarlo del etnógrafo que la critica, se produce así también con una doble intencionalidad: la de los defensores de Menchú para alejarlo de una crítica documental, pero también, la del mismo Stoll (1998) para acercarlo a la ficción. Para Stoll, el texto de Menchú es 
esencialmente mitopoético, en palabras del antropólogo, un relato para justificar una determinada versión del mundo. De todos modos, podríamos objetar, ¿hasta qué punto todo tipo de relato de memorias no es mitopoético?, o, incluso, como han defendido críticos de la antropología como Clifford Geertz o James Clifford, ¿̨asta qué punto las etnografías no pueden ser también leídas como mitopoéticas, es decir, como construcciones textuales para justificar la visión, interpretación, o construcción de una cultura? Desde este punto de vista, de hecho, hasta el relato de Stoll sería mitopoético, ya que se trata de una construcción textual que utiliza procedimientos retóricos para convencer a sus lectores de una determinada versión de los hechos que afectan una colectividad.

\section{Testimonio, etnografía y pactos de lectura}

Estos procedimientos mediante los cuales Stoll edifica su relato son algunas veces semejantes a los llamados tradicionalmente “etnográficos”. De hecho, él se presenta como antropólogo desde el principio del texto, además, como un antropólogo que trabaja "en el campo" recogiendo entrevistas. Estas entrevistas son introducidas en forma de citas directas e indirectas e insertadas en el relato de Stoll. Acude, incluso a veces, al relato de su propia experiencia vivida para presentarse como víctima de las acusaciones de algunos de sus camaradas o de la misma Menchú. Difiere, de todos modos, de las tendencias etnográficas llamadas más autoreflexivas ya que no reconoce que su posición de enunciación condicione su relato. Un relato que, al contrario, se presenta autorizado a partir de algunas de las estrategias de la etnografía tradicional, en una voz a menudo también objetiva y distante, incluso cuando trata de emitir juicios o de presuponer acontecimientos no demostrados. Stoll aspira a presentarse como un observador externo de los hechos, movido en su trabajo por la voluntad de ejercer un ejercicio franco de juicio sobre lo que ha leído y escuchado. ${ }^{30}$

La forma con la que Stoll autoriza su relato es mediatizada por unas determinaciones disciplinarias y genéricas semejantes a las que podrían marcar el discurso mediado por Burgos sobre la vida de Menchú. Nos parece más documental, entre otras cosas, porque tanto su poética como sus determinaciones políticas permanecen ocultas, como lo hacían en los textos etnográficos más realistas. De hecho, Stoll se presenta como el etnólogo que recoge certezas de la voz de los indígenas, que interpreta sus intenciones, y deviene portavoz de su percepción sobre los hechos. La credibilidad de

\footnotetext{
${ }^{30}$ Afirma textualmente: “The main reason I decided against confining myself to the comparison of narratives is that I did not want to give up the frank exercise of judgement, as an outside observer, on the reliability of what I was hearing” (1999a: 217).
} 
Mercé Picornell. Autoría, autoridad y verdad...

Stoll, una vez deshecha la máscara objetiva de su autoridad, puede ser también contradicha. ${ }^{31}$ Considera Carol A. Smith:

The reason is that he takes rather extreme antileft, antipostmodern, antistructuralist, and antisolidarity positions --but he claims to be objective, positioned only in support of voiceless peasants [...] Stoll's polemic seems to arise less form scholarly conviction than from frustration about losing a monopoly on authority. (1999: 26)

En un sentido semejante, se cuestiona Beverley: "Lo que Stoll no pone en duda es el hecho mismo de la tortura y muerte del hermano, sino solo la manera en que Menchú narra ese acontecimiento. La pregunta clave, por lo tanto, no es ¿qué pasó?, sino ¿quién tiene la autoridad de narrar y sobre qué base?" (1998: 277). ${ }^{32}$

De hecho, la forma por excelencia así como se autoriza el relato de Stoll es contradiciendo a Menchú, es decir, contra una forma de autoridad diferente, que considera políticamente mediatizada. No es en vano que Stoll utiliza gran parte de la segunda mitad de su libro para dar informaciones sobre el proceso de redacción del testimonio y de las malas relaciones posteriores entre Menchú y Burgos.

Como he dicho, Stoll nos presenta una Menchú en la que recae toda la autoridad de su relato. Los intentos contradictorios de la indígena para rechazar y adquirir los derechos de autor sobre Me llamo Rigoberta Menchú y así me nació la conciencia son interpretados en el relato de Stoll como fruto de la inseguridad de Menchú respecto a la verdad del testimonio. Sin embargo, en esta revisión del pacto entre autor e informante también puede tener implicaciones el viraje del posicionamiento político de la antropóloga Elizabeth Burgos. Parece ser que una vez asegurado con el Nobel el amplio reconocimiento internacional de su persona y de su lucha, Menchú intentó conseguir los derechos de autor de la obra. Según la antropóloga, Menchú se quería aprovechar del éxito y de los beneficios que estaban

\footnotetext{
31 Como dice Victoria Sanford: "It is ironic that Stoll undetermines testimony as a resource for history when his own reconstructions of history lack credible sources. Testimony has been and continues to be the principal avenue by which semiliterate and illiterate people can communicate with those who wish to understand their struggles" (1999: 44).

${ }^{32}$ Y continúa reafirmando desde un signo contrario al de Stoll la autoridad de Menchú: "Lo que la narración de la muerte del hermano de Rigoberta Menchú nos obliga a reconocer es lo indígena-subalterno no como algo narrado-representado para nosotros, sino como narrador. Narrador con su propio proyecto y poder de gestión--agency-- hegemónicos, porque no es su deseo simplemente narrar su subalternidad. Quiere invertir -violentamente si es necesario y/o posible- los términos y las relaciones sociales que definen esa subalternidad" (1998: 277).
} 
produciendo las múltiples reediciones del texto, aunque hubiese afirmado públicamente en alguna otra ocasión que este no le pertenecía en absoluto y que era fruto de la mistificación de Burgos. ${ }^{33}$

Desde el momento en que es premiada y proyectada como símbolo de la resistencia indígena, Menchú no necesita a Burgos para ser escuchada. Su relato puede difundirse sin la autorización de una antropóloga, escritora o periodista. La cosa se complica cuando son la voz de Burgos y su tarea en la edición del testimonio las que son ocultadas en la presentación del libro. Según Burgos esto se debe, entre otras cosas, al hecho de que su persona resulta poco políticamente correcta a los objetivos de Menchú. Burgos, antropóloga militante en diversas revueltas latinoamericanas, exmujer de Régis Debray y amiga personal de Fidel Castro durante los años setenta, rompe durante los finales de los ochenta con algunas de sus amistades políticas, de la misma forma que Menchú se desvincularía de los grupos a los que había apoyado. ${ }^{34}$ El nuevo entorno de Menchú no cuenta con Burgos para promover la campaña que la hará llegar a Nobel. Explica así la antropóloga el año 1999, es decir, un año después de la edición del libro de Stoll:

The last time that I met Rigoberta Menchú was in Paris in February 1993. I had asked for the meeting --I had tried to see her various times, sending innumerable letters and faxes, without replay-- because I wanted her to explain to me what was happening, why in addition to casting doubt on my role in the book's production she had also declared that I had never sent her any royalties. On this latter theme let me affirm her that I never considered the book my individual project, indeed, I decided on my own, without any prior conditions before undertaking writing, that all of the eventual royalties would go to Rigoberta Menchú. (1999a: 59)

Según dice Burgos, en este encuentro en París, Menchú le explicó que los tiempos habían cambiado y le pidió que renunciase a los derechos de autora de la obra. Cansada de ver su nombre criticado por la misma Menchú y supuestamente fiel al que fue su proyecto inicial, Burgos decidió no interceder por Menchú y dejar las cosas “tal como estaban”. El tono de los diversos artículos de Burgos publicados en 1999 es de cierto resentimiento. Resulta interesante ver cómo su argumentación sobre su

\footnotetext{
${ }^{33}$ Stoll cita las siguientes declaraciones de Menchú en El Periódico de Guatemala el mes de diciembre de 1997, cuando ya podía conocer algunas de las investigaciones de Stoll, refiriéndose a Me llamo Rigoberta Menchú: "It does not belong to me morally, politically or economically. I have respected it greatly because it played an immense role for Guatemala... But I never had the right to say if the text pleased me or not, if it was faithful to the facts of my life. Now my life is mine, therefore I believe that now it is opportune to say that it is not my book... Anyone who has doubts about the work should go to [Elizabeth] because, even legally, I do not have author's rights, royalties, or any of that" (1999: 178).

${ }^{34}$ Dice así Burgos después de exponer su sorpresa ante el perfil que, ante sus ojos, estaba tomando su antigua amiga: "However, I had the good fortune to have a meeting with my old fried Ricardo Ramírez, maximum leader of the EGP, in April 1998 in Guatemala. Aside from the emotion of seeing him again [...] his words calmed me. He assured me that his feelings toward me had not changed and that the EGP had had nothing to do with the position adopted by Rigoberta Menchú with respect to me -that, in any case, she had ceased to be an EGP militant" (1999a: 58).
} 
Mercé Picornell. Autoría, autoridad y verdad...

papel en la composición de la obra utiliza los términos del debate norteamericano sobre lo políticamente correcto:

En el testimonio, el yo narrador está supeditado a una entidad exterior: la figura del escriba que establece las proporciones arquitectónicas del edificio/libro que alberga la voz narradora. Pero los especialistas no admiten el acto de escritura, solo el de transcripción. Ya podemos imaginar lo que sería un libro elaborado a base de la simple transcripción de horas de entrevistas: un texto ilegible y sin forma. En Estados Unidos se me reprocha no haber acatado las normas norteamericanas, que consideran al narrador como único autor y al escritor un simple editor sin tener en cuenta ni la manera ni las circunstancias de realización de la obra. No niego que el tema merezca ser analizado y que exista cierta ambigüedad, sin embargo, la postura norteamericana está motivada por una actitud de condescendencia hacia lo que ellos denominan "sujetos subalternos". De este modo, incurren en un racismo de signo contrario: inconscientemente crean una forma políticamente correcta de racismo. (1999b: 29)

Creo que el tamaño de la citación se justifica por cómo nos muestra a una antropóloga en una posición bastante diferente que la que asumía como mediadora en el prólogo de 1983 al que anteriormente he hecho mención. Burgos asume una posición crítica con la recepción esencialista --y ciertamente, políticamente y culturalmente simplista en las interpretaciones que proyecta-- que un sector de la academia norteamericana ha hecho de obras como la de Menchú. Olvida, sin embargo, que, como hemos visto, esta misma esencialización es inducida por los términos de su prólogo y su disposición del relato. No tiene en cuenta tampoco que desde los años noventa el modelo de autoridad al que hace mención ha sido altamente cuestionado por los críticos que tratan del testimonio. En la apropiación y representación de la diferencia que Burgos critica ella misma tiene un papel destacado.

Burgos se defiende de las acusaciones respecto a las modificaciones sobre el discurso oral inicial de Menchú comparando sus procedimientos con los que habían utilizado otros gestores o mediadores de testimonios. Estos muy a menudo han optado por utilizar un seudónimo para referirse a sus informantes (es el caso del personaje de "Jesusa Palancares" de Hasta no verte Jesús mío, escrito por Elena Poniatowska) o, todavía más a menudo, utilizan un término genérico en el título de la obra (es el caso de Biografía de un cimarrón). Dice así irónicamente Burgos hacia el final de su artículo en un comentario que, de alguna forma, reafirma su poder sobre la difusión y autorización del testimonio: "Perhaps that was my mistake: if instead of giving it the name of Rigoberta Menchú I had opted for Habla una India de Guatemala, history might have treated me differently" (1999a: 61).

Este comentario puede servirnos también como indicio para notar cómo la crítica de Burgos difiere de la de Stoll en dos términos. En primer lugar, Burgos reafirma su papel en la composición del relata explicitando, casi veinte años después de la construcción del libro, algunos de los procedimientos que utilizó y el motivo de decisiones como la de incluir fragmentos de descripción cultural que algunos de sus compañeros habían considerado inadecuados. Stoll, en cambio, los explica como estrategias de 
Menchú para mostrarse como la indígena auténtica que, según el antropólogo, no es por completo. En el relato del norteamericano, Burgos es una antropóloga no solo inocente ante las estrategias malévolas de Menchú, sino transparente cuando se trata de transmitir $s u$ voluntad representativa y $s u$ diferencia cultural.

En segundo lugar, Burgos expone el planteamiento político que la llevó a participar en la conversión de Menchú en símbolo de los indígenas. Lo que no le gusta es la forma como ha ido desvaneciéndose el significado de este símbolo hacia convertirse en una figura quizás más vacía o simple políticamente hablando, pero también más útil para la consecución de un consenso. ${ }^{35}$ Stoll, en cambio, rechaza el sentido de esta proyección simbólica que ha conseguido el personaje de Menchú. De hecho, su tarea toma la apariencia de una desmitificación que podríamos valorar como positiva cuando la función de esta proyección representativa, siempre simplificadora de la heterogeneidad de un colectivo, parece que ya no es necesaria. De todos modos, tampoco no es esta exactamente la opción de Stoll quien, de hecho, utiliza el mismo sentido simbólico que critica para reafirmarse en un posicionamiento político opuesto. Desde la excusa de revisar el texto de Menchú, Stoll se quita de delante el discurso de los 500 años de resistencia indígena que el premio Nobel parecía querer reconocer como válido en la fecha de 1992. En cierta forma, Stoll cae en el mismo equívoco que denuncia ya que utiliza Rigoberta a partir del procedimiento metonímico que la hace representativa de un grupo pero invirtiendo el interés político de esta proyección. Invierte la función de la importancia mediática del personaje de Menchú para difundir sus propias tesis. Desautorizando Menchú pretende revisar la legitimidad de un proyecto político que supera el discurso de la Nobel y que se perfila como mucho más heterogéneo y complejo que en las visiones parciales que pueden plantear tanto el testimonio de Burgos y Menchú como, por motivos diferentes, el libro de Stoll.

\section{Conclusiones parciales, verdades ambiguas}

Cuando en el título de este artículo propongo una lectura "en frío" de la polémica Menchú-Stoll, no pretendo que el tema sobre el que se discute sea un tema resuelto u olvidado. Testimonios como el de Menchú contribuyen ciertamente a esta función: la de permitir el reconocimiento del dolor que causó el

\footnotetext{
35 Acaba así su articulo diciendo: “The icon into which Rigoberta Menchú has been converted has contributed to the fact that the just demands of indigenous peoples have become just one more fashion, emptied of content. She has been transformed into a tree that obscures the forest; instead of being a representative she is, rather, a personification of representation. The voice that denounced has been transformed into an invitee of the establishment, distancing herself from the popular movement [...]. Nevertheless, it is not impossible to imagine a future in which there are moments of extreme tension between Guatemala's ladino and indigenous peoples and in which Rigoberta Menchú -given her power to attract attention internationally and ability to weave alliances with the ladino world- could become just the person to reestablish equilibrium between them" (1999b: 62).
} 
genocidio que, entre otros, provocó alguien que se ha mantenido en plena actualidad como el general Efraín Ríos Montt, candidato derrotado a la presidencia en 2003 --cuando la polémica ya remitía-- y condenado en 2013 a ochenta años de cárcel por el delito de genocidio: condena anulada diez días después por la Corte de Constitucionalidad de Guatemala. ${ }^{36}$ Una lectura "en frío" es, en cambio, la que permite analizar cómo se autorizan algunos discursos para revisar en qué puntos sus legitimidades flaquean. En este artículo he analizado cómo se construyen las tesis de Stoll en Rigoberta Menchú and the Story of All Poor Guatemalans. Mi intención era mostrar cómo algunos de sus argumentos están viciados por la voluntad política de construir un discurso no solo contra la "verdad" que el testimonio de Menchú construye, sino contra la legitimidad de los argumentos de los que apoyaron o defendieron su causa (intelectuales estadounidenses incluidos). He defendido que, al proyectar las supuestas falsedades de la Nobel al colectivo al que esta, de alguna forma, representa, Stoll incurre en la trampa testimonial que denuncia, por lo cual su discurso es insostenible aunque disfrace su incoherencia con estrategias de documentación más tradicionales y también, quizás, menos ambiguas que las que presenta el testimonio. Demostrando que el relato de Menchú es un fraude, pretende proyectar su experiencia para despreciar no solo la opción política que representa, sino también los procedimientos críticos de sus camaradas académicos que han optado por otros modos de representación menos convencionales. Presenta asía asus compañeros antropólogos tan preocupados por la tarea de recuperar o presentar la voz del indígena que no disciernen entre la verdad y la mentira y se creen, en cierta forma, el mito que ellos mismos han creado. ${ }^{37}$

Sí que es cierto, de todos modos, que hay alguna forma de leer la opción de Stoll como algo "legítimo". Podemos pensar que con la crítica de Stoll se acaba revirtiendo la posición de objeto de estudio a la cual los subalternos se habían visto reducidos. De hecho, Stoll toma el relato de Menchú --ya que no evalúa la mediación de Burgos como algo que condicione la expresión de la informante, y aquí creo que se equivoca- como un discurso que puede contradecir con estrategias parecidas a las que se utilizan en medios académicos. La importancia de la voz de la indígena ha hecho que sea tomada en cuenta, y no simplemente alejada de los medios académicos a los que no puede acceder, o tomada como caso "diferente" cuya verdad no tiene relevancia histórica o etnográfica. Puede que, en el fondo, sea este el precio de entrar de alguna forma en el canon, el de tener que defender la necesidad de una perspectiva crítica diferente, pero que no se sostiene porque sea más "fuerte”, más "referencial” o más “autorizada",

\footnotetext{
36 Ver, por ejemplo, María R. Sahuquillo (2013). “Diez días de justicia”, ElPaís, 24 de Mayo.

37 Afirma Stoll:“[S]ome colleagues also warned that a white anthropologist did not have the right to undermine a Native American's right to tell her own story. Embarrassed by their association with Western power, anthropologists are increasingly leery of imposing their own interpretative framework on the narratives of others, especially when they are victims of colonialism" (1999a: 216)
} 
Mercé Picornell. Autoría, autoridad y verdad...

sino porque propone otra forma de comprender el mundo y sobre todo otra manera, no sé si más integradora, más consciente o más comprometida, de representarlo. 


\section{Bibliografía}

Arias, Arturo (1996). “From Peasant to National Symbol”. Carey-Webb, Allen; Benz, Stephen (eds.). Teaching and Testimony. Rigoberta Menchú and the North American Classroom. New York: Suny Press: 29-47.

Arias, Arturo. “After the Rigoberta Menchú Controversy: Lesson Learned About the Nature of Subalternity and the Specifics of the Indigenous Subject". Modern Language Notes, 117, 2 (2002): 481-505.

Barnet, Miguel (1998[1981]). La fuente viva. La Habana: Editorial Letras Cubanas.

Beverley, John (1998). "Siete aproximaciones al "problema indígena". Moraña, Mabel (ed.). Indigenismo hacia el fin del milenio. Pittsburgh: Instituto Internacional de Literatura Iberoamericana, 269-283.

Benz, Stephen (1996). "Culture Shock and I, Rigoberta Menchü”, Carey-Webb, Allen \& Benz, Steven (eds.). Teaching and Testimony. Rigoberta Menchú and the North American Classroom. New York: Suny Press: 19-28.

Beverley, John (1999). Subalternity and Representation. Arguments in Cultural Theory. Durham and London: Duke University Press.

Binford, Leigh. "Empowered Speech: Social Fields, Testimonio and the Stoll-Menchú Debate". Identities 8, 1(2001): 105-133.

Burgos, Elisabeth. “Guatemala: voyage au bout de l'horreur”. Le Nouvel Observateur, 24 de abril (1982): 130-146.

Burgos, Elizabeth (1998[1983]). Me llamo Rigoberta Menchú y así me nació la conciencia. Barcelona: Seix Barral.

Burgos, Elizabeth. "The Story of a Testimonio". Latin American Perspectives 26, 6 (1999a): 53-63.

Burgos, Elizabeth. "Poner voz a una conciencia”. Lateral 52 (1999b):19-20.

Canby, Peter. "La verdad acerca de Rigoberta Menchú". The New York Times Review of Books XLVI, 6 (1999).

Carey-Webb, Allen \& Benz, Steven (eds.) (1996). Teaching and Testimony. Rigoberta Menchú and the North American Classroom. New York: Suny Press. 
Mercé Picornell. Autoría, autoridad y verdad...

Carr, Robert. "Re-presentado el testimonio. Notas sobre el cruce divisorio primer mundo/tercer mundo". Revista de crítica literaria latinoamericana 36 (1992): 73-94.

Dröscher, Barbara. "El testimonio y los intelectuales en el triángulo atlántico". Istmo. Revista virtual de estudios de literatura y cultura centroamericana 2 (2001)

D’Souza, Dinesh (1991). Illiberal Education. The Politics of Race and Sex on Campus. New York: The Free Press.

Fischer, Edward D. (2001). "Derechos humanos y relativismo cultural. La ética antropológica en el área maya”. Pitarch, Pedro y López, Julián (coord.). Los derechos humanos en tierras mayas. Madrid: Sociedad Española de Estudios Mayas, 291-310.

Gilmore, Leigh (2001). The Limits of Autobiography. Trauma and Testimony. Ithaca and London: Cornell University Press.

Gugelberger, Georg M. "Introduction”, al monográfico: "Voice of the Voiceless. Testimonial Literature in Latin America". Latin American Perspectives 91 (1991): 3-9.

Gugelberger, Georg M. "Stollwerk or Bulwark? David Meets Goliath and the Continuation of the Testimonio Debate”. Latin American Perspectives 26, 6 (1999): 47-52.

Menchú, Rigoberta. "Los que me atacan humillan a las víctimas". El País, 24 de enero (1999): 6 y 7.

Ochando, Carmen (1998). La memoria en el espejo. Aproximación a la escritura testimonial. Barcelona: Anthropos.

Picornell, Mercè (2003). Política i poètica de l'etnoficció. Escriptura testimonial y representació de la veu subalterna. Tesis doctoral inédita presentada el 29 de septiembre del 2003 en la Universidad Autónoma de Barcelona.

Picornell, Mercè. "Gestores de la voz ajena. El intelectual como mediador en la escritura testimonial”. Brújula. Revista interdisciplinaria sobre estudios latinoamericanos 1, 1 (2002): 37-53.

Rus, Jan. "Introduction", al monográfico: "If Truth Be Told. A Forum on Stoll and Menchú". Latin American Perspectives 26, 6 (1999): 5-14.

Sanford, Victoria. "Between Rigoberta Menchú and La Violencia: Deconstructing David Stoll's History of Guatemala". Latin American Perspectives 26, 6 (1999): 38-46.

Sklodowska, Elzbieta (1992). Testimonio hispanoamericano. Historia, teoría, poética. Nueva York: Peter Lang. 
Mercé Picornell. Autoría, autoridad y verdad...

Sklodowska, Elzbieta. “Testimonio mediatizado: ¿Ventriloquia o heteroglosia?”. Revista de crítica literaria latinoamericana 19, 38 (1993): 81-90.

Smith, Carol A. "Why Write an Exposé of Rigoberta Menchú?". Latin American Perspectives 26, 6 (1999): 15-28.

Sommer, Doris (1988). “Not Just a Personal Story’: Women’s Testimonios and the Plural Self”. Brondzki, Bella y Schenck, Celeste (eds). Life/Lines. Theorizing Women's Autobiographies. Ithaca: Cornell University Press, 107-130.

Spivak, Gayatri Chakravorty (1988). "Can The Subaltern Speak?”, Cary Nelson \& Lawrence Grossberg eds. Marxism and the Interpretation of Culture. London, Macmillan.

Stoll, David (1999a). Rigoberta Menchú and the Story of All Poor Guatemalans. Boulder, Westview.

Stoll, David. "Life Story as Mythopoesis”. Anthropology News 39, 4 (1998): 9-11.

Stoll, David. "Rigoberta Menchú and the Last-Resort Paradigm”. Latin American Perspectives 26, 6 (1999b): 70-80.

Stoll, David. “Los testimonios silenciados”. Lateral52 (1999b): 32.

Williams, Gareth (1996). "The Fantasies of Cultural Exchange in Latin American Subaltern Studies”. Gugelberger, Georg (ed.). The Real Thing. Testimonial Discourse in Latin America. Durham: Duke University Press, 254-265. 